American Journal of Pharmaceutical Education 2018; 82 (5) Article 6296.

\title{
RESEARCH
}

\section{Pharmacy Student Knowledge, Confidence and Attitudes Toward Medical Cannabis and Curricular Coverage}

\author{
Frank J. Caligiuri, PharmD, Erin E. Ulrich, PhD, Kelli Jo Welter \\ Drake University College of Pharmacy and Health Sciences, Des Moines, Iowa \\ Submitted January 24, 2017; accepted February 11, 2017; published June 2018.
}

Objective. To assess pharmacy student confidence in their knowledge of qualifying conditions for medical cannabis use in the US and their attitudes toward curricular coverage of medical cannabis.

Methods. Students were asked to complete an electronic survey to measure knowledge and confidence in various domains of medical cannabis treatment, including qualifying conditions, adverse effects, and other patient care skills.

Results. There were 238 students who completed the survey. Responses to all domains and their corresponding confidence levels displayed a lack in confidence. The only domain wherein students had confidence in was their ability to retrieve related drug information. Nearly $80 \%$ of students felt that the topic of medical cannabis should be added to existing curricula within the next five years.

Conclusion. With the prevalence of cannabis programs and knowledge gap, pharmacy schools should consider coverage of medical cannabis in the curricula.

Keywords: medical marijuana, medical cannabis, pharmacy students, knowledge, pharmacy education

\section{INTRODUCTION}

In the United States, cannabis remains a Schedule I controlled substance with no accepted medical use under federal law. However, as of May 2018, there are 29 states that permit the use of cannabis in various forms for symptomatic relief of various qualifying conditions. These 29 states have "comprehensive" medical cannabis programs that allow patients to use different cannabis products and routes of administration for various conditions approved at the state level. ${ }^{1}$ In addition to these 29 states, there are also 17 states with restricted programs that allow for the sole use cannabidiol (CBD) preparations, known commonly as "CBD oil." 2

Cannabidiol preparations have been shown to be effective for epilepsy without producing psychoactivity or the "high" traditionally associated with tetrahydrocannabinol (THC), and has been approved with little pushback in many state legislatures for this reason. ${ }^{3}$ Health care professionals may be significantly involved with the medical cannabis programs in their state. Many, but not all, states have established medical boards with various health professionals of different disciplines to evaluate the most up-to-date literature regarding risks and benefits of cannabis use for various conditions. ${ }^{1}$

Corresponding Author: Frank Caligiuri, Drake University College of Pharmacy and Health Sciences, Cline Atrium 008, 2507 University Ave., Des Moines, IA 50311. Tel: 515-2713936. Fax: 515-271-4569. E-mail: frank.caligiuri@drake.edu
As patient access increases, so will the number of questions surrounding this potential treatment option. Questions typically addressed by pharmacists such as efficacy, safety, dosage, and drug interactions will be difficult to accurately address given the lack of clinical trials, lack of oversight from the Food and Drug Administration (FDA), and the conflict between state and federal laws regarding the substance. Additionally, there are states such as Connecticut and Minnesota where pharmacists are dispensing non-FDA approved cannabis products without Drug Enforcement Admininstration (DEA) licensure. ${ }^{4,5}$ With various state laws that conflict with federal laws, the role of pharmacists in respect to medical cannabis is an emerging area of interest in the US and other countries. ${ }^{4-7}$

In 2007, Seamon and colleagues' review titled "Medical Marijuana and the Developing Role of the Pharmacist" concluded that "pharmacists need to understand the complex legal framework surrounding this issue so that they can protect themselves and better serve their patients." They outlined a 10-step systematic approach to deal with the issue of medical cannabis for pharmacists. $^{6}$ In 2014, the American Pharmacists Association (APhA) formulated a policy titled "Role of the Pharmacist in the Care of Patients Using Cannabis." In this policy, they describe the responsibilities pharmacists have while educating patients about medical cannabis. ${ }^{7}$ These publications may have underestimated the significant role that pharmacists have been asked to play within medical cannabis programs. ${ }^{4,5}$ 


\section{American Journal of Pharmaceutical Education 2018; 82 (5) Article 6296.}

While medical cannabis programs remain controversial, pharmacists in all states may dispense cannabis-based products approved by the FDA. Dronabinol, a synthetic version of tetrahydrocannabinol (THC), first approved in 1985 by the FDA for nausea and vomiting due to chemotherapy, and its analog nabilone have been available for over 30 years. ${ }^{8}$ Additionally, there is a resurgence in product development in the area of cannabinoid-based medications. There are two additional cannabis-based products currently under FDA review. Epidiolex is a product containing purified CBD and is available under the orphan drug program for a limited number of patients. ${ }^{9}$ Sativex, available in 16 countries, is a combination of THC and CBD. ${ }^{10}$ Regardless of where pharmacists practice, the topics of medical cannabis and cannabis-based medications will certainly be an area pharmacists will be expected to be knowledgeable and to be able to address patient and provider questions. Since the endocannabinoid system and cannabinoid pharmacology have not been a large component of pharmacy and medical education, there is an increased need to address this area in curricula to better prepare future practitioners.

Because individual states and pharmacy organizations are moving on this controversial topic at different paces, it is important to understand pharmacist and pharmacy student attitudes on this treatment option to ensure they are prepared to work with patients when entering practice. A few studies have evaluated practitioners' attitudes toward the use of medical cannabis. ${ }^{11-16}$ These studies surveyed health care professionals from various disciplines with mixed results. Doblin and Kleiman as well as Schwartz and colleagues provided two early studies that evaluated the oncologists' perspective and about one-third were supportive of medical cannabis use. ${ }^{1,12}$ Charuvastra and colleagues' study from 2005 evaluated several different types of licensed physicians outside of oncology setting. They found that among a national sample of psychiatrists, obstetrician-gynecologists, internal medicine, family practice, and addiction specialists, support for prescribing cannabis was $36.1 \%$ of its 960 respondents and $37.8 \%$ were opposed. ${ }^{13}$ Konrad and Reid surveyed family physicians in Colorado, a state currently with both medical and recreational cannabis laws, on their attitudes toward medical cannabis with interesting results in 2013. Among the 520 respondents, 19\% supported prescribing cannabis and $46 \%$ were opposed. ${ }^{14}$ Uritsky and colleagues evaluated the knowledge, attitudes, and experience among health professional employees of national hospice chain. The sample of 194 respondents was composed of $68 \%$ nurses and only $6.8 \%$ physicians. Among these respondents, $90 \%$ were supportive of the use of medical cannabis for palliative symptoms and $86 \%$ agreed that cannabis has therapeutic benefits. ${ }^{15}$

There are very few studies that have specifically examined attitudes among health professions students. Among health professional students, Chan and colleagues evaluated attitudes and beliefs regarding cannabis in medical students in Colorado. They found that students support cannabis law reform, medical uses, and increased research, but have concerns regarding risks use, and are hesitant to recommend cannabis to patients. However, this study did not measure knowledge of medical cannabis and had a low response rate of $37 \% .^{17}$

Moeller and colleagues provides the only previous publication addressing health professional students' knowledge of medical cannabis in addition to their attitudes. ${ }^{18}$ This study evaluated knowledge of adverse reactions and indications based on 14 state laws that were enacted at the time of their survey development. The results of this study demonstrated that the majority of students were unable to identify state permitted uses of cannabis outside of cancer and glaucoma. Furthermore, students did not feel comfortable answering patients' questions regarding efficacy, safety or drug interactions related to cannabis therapy. As stated earlier, 45 states now have some form of medical cannabis legislation, 29 "comprehensive" medical programs and 16 "CBD only" programs. ${ }^{1,2}$

In this changing environment, educators need to prepare students to understand the pharmacology, risks, benefits and laws associated with medical cannabis programs so that they have the knowledge and skills required to serve the public. The objective of this study was to examine not only student knowledge but also their confidence in that knowledge. This study has addressed the gaps in previous studies by expanding the domains of knowledge beyond the adverse reaction and permitted uses, and included measures of confidence in patient care skills such as communication, identifying potential drug interactions and retrieving related drug information. This study also evaluated pharmacy students' attitudes regarding the acceptance of medical cannabis and curricular coverage on this topic.

\section{METHODS}

This study used a one-time, anonymous, online questionnaire of first-, second-, and third year pharmacy students (P1-P3) at a private, Midwestern university. In the final year of pharmacy school (P4 year), students were on rotation around the United States and internationally, and therefore were excluded from this study due to low response.

The questionnaire was pilot tested by six pharmacy students, two from each year. Alterations were made by research investigators. The survey was then again reviewed 


\section{American Journal of Pharmaceutical Education 2018; 82 (5) Article 6296.}

by three pharmacy students. No changes were determined to be needed during the second review. This study was approved by the university's institutional review board (IRB).

The Pharmacy Skills and Application (PSA) course series is required in each semester of the pharmacy curriculum. Students were offered the opportunity to voluntarily participate in the survey from these courses as they are offered each semeseter during the P1 through P3 years. The course instructors were contacted and provided time at the end of their course for the students to complete the 20-30-minute questionnaire. The course instructor was instructed to read an IRB script about the study and provided students with the Qualtrics (Qualtrics, Provo, UT) link to the questionnaire. If students volunteered, they completed the questionnaire on their own laptops. Informed consent was obtained via online questionnaire. If students did not volunteer to take the questionnaire, they were able to leave class.

Due to IRB concern of reputable harm and potential of subject identification, only two demographic variables were captured: gender and year in pharmacy school. The questionnaire included one item to determine if the student obtained any formal education on medical cannabis through school, work, webinars, or other formal training. Subjects were asked, "Have you received any formal education or training on medical cannabis at any time?" Response options for this item was yes/no. At this institution, students are presented with little information within the curriculum on the physiologic functions of the endocannabinoid system or on cannabinoids within the physiology or pharmacology coursework. Some information is presented in terms of known receptors and substance abuse considerations. P3 students received a single 90-minute lecture within their law and ethics course. The focus of this lecture was on state and federal laws but background information on the endocannabinoid system, cannabinoid pharmacology, and routes of administration were presented.

Subjects were asked to self-evaluate their level of knowledge/confidence on 11 different domains of medical cannabis therapy and their knowledge of state laws. Response options were not confident, somewhat confident, and confident. In Ebert and colleagues' study, Israeli physician participants were asked to self-evaluate their knowledge (on a $0-5$ scale) on the three domains of pharmacology and medical indications, routes of administration and dosage forms, and risks and side effects of medical cannabis ${ }^{19}$ Our study expanded that survey design into additional domains regarding medical cannabis and state laws to measure student knowledge and confidence.

Detailed knowledge of qualifying conditions for medical cannabis use among US states and adverse effects of use were captured. When prompted with a condition or adverse reaction, available response options were "true," "false," or "don't know." If subjects stated "true" or "false," they were asked how confident they were in their previous response of "true" or "false." Response options were "not very confident," "fairly confident," and "extremely confident." Pharmacists often answer questions about therapies that patients first learn about through the media. The survey sought to measure student knowledge along with confidence as a surrogate for students being able to answer a patient's question confidently related to that domain. The Moeller and Woods study measured knowledge with a true/false format for state-permitted medical uses and adverse effects. However, students may be able to choose the correct response based on chance or a guess. ${ }^{18}$

A list of 20 symptoms was given to students and they were asked to identify if each symptom was an adverse effect/side effect of cannabis use. Fifteen were actual adverse effects. Moeller's previous study also used the methodology of having students select from a list that contained both correct and incorrect responses and this method was duplicated in our study. ${ }^{18}$ A systematic review and meta-analysis of cannabinoids for medical use conducted by Whiting and colleagues that reported the incidence for each adverse effect was used to determine if that adverse effect was true/correct. ${ }^{20}$ It is important for students to be able to distinguish between actual and perceived adverse reactions of cannabis use. Therefore the meta-analysis was used for scoring the responses.

Medical cannabis legislation typically uses the term "qualifying conditions" to describe permitted medical uses of cannabis within a state law. A list of 22 conditions was provided to students and they were asked to identify which were qualifying conditions in more than one US state by marking "true" or "false." Responses were considered "correct" if they were approved in two or more of state programs at the time of survey development. Based on this definition of state-approved indications, 16 of the 22 options were considered correct responses while the remaining six were not. ${ }^{1,2}$ At the time of survey development, there were 23 "comprehensive" state programs as described above and 16 states with CBD legislation. This methodology was based on the previous Moeller publication, however, that survey evaluated only conditions that were present in 14 states at the time of its development. With the recent and rapid expansion of programs, especially CBD only programs, our study evaluated knowledge of qualifying conditions in 39 states with medical cannabis laws at the time of our survey instrument development. ${ }^{1,2}$

Six items captured subjects' attitudes of medical cannabis being integrated into pharmacy curriculum within the next five years. The state laws surrounding the medical 


\section{American Journal of Pharmaceutical Education 2018; 82 (5) Article 6296.}

use of cannabis are rapidly changing. In 2014 alone, there were 16 states that adopted either a medical cannabis program or a cannabidiol only program. ${ }^{1,2}$ Additionally, several new cannabis-based products are expecting FDA approval in the next two to five years. ${ }^{9,10}$ Therefore, with the changing landscape, five years was selected as a potential time window to address this curricular gap as there may be an immediate need for education. Response options were a 5-point Likert scale ranging from "strongly disagree" to "strongly agree."

This was a descriptive study to determine where student pharmacists are in their knowledge base and their attitudes toward medical cannabis and related curricula. Frequencies and descriptives were conducted on all domains of interest: demographics, knowledge and confidence of state-permitted qualifying conditions, knowledge and confidence in adverse reactions, confidence of general areas of patient care regarding medical cannabis, and attitude toward medical cannabis education in pharmacy curricula.

\section{RESULTS}

There were 238 students out of a possible 315 who completed the survey $(76 \%$ response rate; $\mathrm{P} 1=86$, $\mathrm{P} 2=97, \mathrm{P} 3=55)$. The remaining students chose not to participate. The majority of respondents were female $(\mathrm{n}=168,70.6 \%)$. There were 86 (36.1\%) P1 students, 97 (40.8\%) P2 students, and 55 (23.1\%) P3 students who completed the questionnaire. Only 8 (3.4\%) reported receiving any prior medical cannabis education.

Table 1 shows student responses regarding their knowledge of qualifying conditions and their confidence for those responses. Students did well when identifying conditions for which cannabis is not permitted and were also confident in these responses. For example, the majority $(85 \%)$ of students responded that vertigo is not a qualifying condition and were $94 \%$ confident in their response.

For conditions where cannabis use is permitted, responses and confidence were less accurate. For example, only $51 \%$ identified nausea as a qualifying condition and only $20 \%$ of those students felt confident in their response. Cancer was identified as a qualifying condition by $79 \%$ of students, however, only $34 \%$ felt confident in this response. When isolating for only students who had the correct response and were also confident, the top qualifying conditions identified were epilepsy (39\%), cancer (33\%), anorexia (24\%), and nausea (19\%). In contrast, $95 \%$ of students responded that "hepatitis" is not a qualifying condition and were $99 \%$ confident in this response, although incorrect.

In terms of student knowledge of adverse reactions, responses and confidence varied widely and are included in Table 2. Students identified disorientation of time (58\%),
Table 1. Pharmacy Student Knowledge of Qualifying Conditions $^{\mathrm{a}}$ for Medical Cannabis among US states $(\mathrm{N}=238)$

\begin{tabular}{|c|c|c|c|}
\hline Condition & $\begin{array}{l}\text { Correct } \\
\text { N }(\%)\end{array}$ & $\begin{array}{c}\text { Confident } \\
\text { N (\%) }\end{array}$ & $\begin{array}{c}\text { Correct and } \\
\text { Confident } \\
\text { N }(\%)\end{array}$ \\
\hline Alzheimer's Disease & $22(9)$ & $13(5)$ & $4(2)$ \\
\hline $\begin{array}{l}\text { Amyotrophic Lateral } \\
\text { Sclerosis (ALS) }\end{array}$ & $71(30)$ & $23(10)$ & $14(6)$ \\
\hline Anorexia & $128(54)$ & $61(13)$ & $58(12)$ \\
\hline Anxiety $^{\mathrm{b}}$ & $22(9)$ & $40(17)$ & $2(1)$ \\
\hline Asthma $^{b}$ & $92(39)$ & $17(7)$ & $10(4)$ \\
\hline Cancer & $188(79)$ & $80(34)$ & $79(33)$ \\
\hline Crohn's Disease & $48(20)$ & $23(10)$ & $16(7)$ \\
\hline Cystic Fibrosis $^{\mathrm{b}}$ & 43 (18) & $15(6)$ & $3(1)$ \\
\hline Depression $^{\mathrm{b}}$ & $33(14)$ & $30(13)$ & $3(1)$ \\
\hline Epilepsy & $177(74)$ & $92(39)$ & $92(39)$ \\
\hline Glaucoma & $118(50)$ & $53(22)$ & $52(22)$ \\
\hline Hepatitis & $12(5)$ & $12(5)$ & $3(1)$ \\
\hline $\begin{array}{l}\text { Human } \\
\text { Immunodeficiency } \\
\text { Virus (HIV) }\end{array}$ & $88(37)$ & $40(17)$ & 34 (14) \\
\hline Migraines & $130(55)$ & $36(15)$ & $31(13)$ \\
\hline Multiple Sclerosis (MS) & $101(42)$ & $32(13)$ & $27(11)$ \\
\hline Nausea & $122(51)$ & $48(20)$ & $44(18)$ \\
\hline Parkinson's Disease & $59(25)$ & $17(7)$ & $11(5)$ \\
\hline $\begin{array}{l}\text { Post-traumatic Stress } \\
\text { Disorder (PTSD) }\end{array}$ & $107(45)$ & $29(12)$ & $26(11)$ \\
\hline Schizophrenia $^{\mathrm{b}}$ & $41(17)$ & $17(7)$ & $4(2)$ \\
\hline Spasms & $87(37)$ & $26(11)$ & $19(8)$ \\
\hline Tourette's Syndrome & $54(23)$ & $14(6)$ & $7(3)$ \\
\hline Vertigo $^{\mathrm{b}}$ & $36(15)$ & $15(6)$ & $0(0)$ \\
\hline
\end{tabular}

${ }^{a}$ A qualifying condition was considered correct if approved in two or more state medical cannabis programs

${ }^{\mathrm{b}}$ These are not qualifying conditions for medical cannabis among US states. Reverse coding was conducted on these. Therefore, the correct answer is "False."

euphoria (58\%), somnolence (57\%), problems with motor coordination $(55 \%)$ as adverse reactions but confidence in these responses did not exceed $17 \%$. In contrast, only $36 \%$ identified dry mouth as an adverse reaction, which is among the most common reported in the recent systematic analysis of cannabinoids by Whiting. ${ }^{20}$ When isolating for only students who had the correct response and were confident, the top adverse reactions identified were euphoria (18\%) and disorientation to time (11\%). All other responses measured less than $10 \%$ for the combined correct response and confidence measure.

Table 3 displays students' self-reported confidence measures for various domains (ie, pharmacokinetics, pharmacology, patient education, etc.) of medical cannabis use. Students were most confident in their ability to search and retrieve drug information related to medical 


\section{American Journal of Pharmaceutical Education 2018; 82 (5) Article 6296.}

Table 2. Pharmacy Student Knowledge of Adverse Effects of Medical Cannabis Use $(\mathrm{N}=238)$

\begin{tabular}{|c|c|c|c|}
\hline Adverse Reaction & $\begin{array}{l}\text { Correct } \\
\text { N }(\%)\end{array}$ & $\begin{array}{c}\text { Confident } \\
\text { N }(\%)\end{array}$ & $\begin{array}{c}\text { Correct and } \\
\text { Confident } \\
\text { N }(\%)\end{array}$ \\
\hline Anemia $^{\mathrm{a}}$ & $59(25)$ & $16(7)$ & $8(3)$ \\
\hline Cataracts $^{\mathrm{a}}$ & $78(33)$ & $19(8)$ & $15(6)$ \\
\hline Confusion & $103(43)$ & $15(6)$ & $9(4)$ \\
\hline Constipation $^{\mathrm{a}}$ & $49(21)$ & $12(5)$ & $5(2)$ \\
\hline Depressed mood & $27(11)$ & $15(6)$ & $1(0)$ \\
\hline Diabetes $^{\mathrm{a}}$ & $81(34)$ & $17(7)$ & $14(6)$ \\
\hline Diarrhea & $15(6)$ & $14(6)$ & $0(0)$ \\
\hline Disorientation of time & $137(58)$ & $33(14)$ & $27(11)$ \\
\hline Dizziness & $89(37)$ & $14(6)$ & $7(3)$ \\
\hline Drowsiness & $119(50)$ & $19(8)$ & $15(6)$ \\
\hline Dry mouth & $85(36)$ & $27(11)$ & $22(9)$ \\
\hline Euphoria & $137(58)$ & $41(17)$ & $38(16)$ \\
\hline Fatigue & $81(34)$ & $20(8)$ & $14(6)$ \\
\hline Increased bleeding $^{\mathrm{a}}$ & $64(27)$ & $13(6)$ & $8(3)$ \\
\hline Lack of energy & $84(35)$ & $16(7)$ & $12(5)$ \\
\hline $\begin{array}{l}\text { Problems with motor } \\
\text { coordination }\end{array}$ & $130(55)$ & $23(10)$ & $20(8)$ \\
\hline Nausea & 45 (19) & $28(12)$ & $3(1)$ \\
\hline Sleepiness/Somnolence & $135(57)$ & $28(12)$ & $26(11)$ \\
\hline Visual hallucinations & $88(37)$ & $24(10)$ & $10(4)$ \\
\hline Vomiting & $30(13)$ & $21(9)$ & $3(1)$ \\
\hline
\end{tabular}

${ }^{\mathrm{a}}$ These are not adverse reactions of medical cannabis use. Reverse coding was conducted on these. Therefore, the correct answer is "False."

cannabis (19\% confident, $40 \%$ somewhat confident). The majority of students reported not being confident in the domains relating to communication with patients or health care providers on the subject. Students reported "not confident" at high rates for the following areas: talking with patients about risks (77\%); talking with other health care providers (77\%); talking with patients about dosage forms (74\%); talking with patients about benefits $(73 \%)$.

In addition to pharmacy student knowledge and confidence, student attitudes toward education and curricula related to medical cannabis were measured (Table 4). Results show an overwhelming majority of students feel that the topic of medical cannabis should be covered within either elective courses $(84 \%)$ or required in the pharmacy curricula (72\%). The highest level of agreement was regarding the subject of state laws regarding medical cannabis use. Ninety-three percent of students agreed that pharmacy students should receive education on state laws specifically. Of note, $90 \%$ of students agreed that education on how to counsel patients regarding the risks and benefits of medical cannabis should be included in curricula within the next five years.

\section{DISCUSSION}

Overall, pharmacy students were generally able to identify conditions for which medical cannabis use is not permitted for in US states (ie, vertigo, cystic fibrosis) and were confident in those responses. However, for conditions where medical cannabis is permitted, many students were unable to confidently identify these qualifying conditions with the exceptions being epilepsy (39\%) and cancer (33\%) (Table 1). Many conditions such as multiple sclerosis, Crohn's disease, and nausea that are qualifying conditions in many states were identified confidently by less than $20 \%$ of students, which was a finding far lower than expected. ${ }^{1}$

With widespread attention of non-psychoactive cannabidiol products for refractory seizures, it was expected to see epilepsy identified as a qualifying condition by students at $39 \%{ }^{2}$ This may also be a reflection of the particular location where the survey was conducted as cannabidiol preparations or CBD oil for refractory epilepsy was the only qualifying condition in the state where the study was conducted at that time. However, a higher percentage than 39\% may have been expected with the rapid expansion of CBD programs, local and national attention, and given that epilepsy is a qualifying condition in nearly every state with a medical cannabis or CBD program. ${ }^{1-3}$

Students were able to identify correctly and confidently that anorexia and nausea are qualifying conditions at $25 \%$ and $19 \%$, respectively. While these conditions are among the highest percentages, they may be considered low given that anorexia and nausea are also FDA-approved indications for cannabis-based pharmaceutical products, dronabinol and nabilone. ${ }^{8}$ The findings may reflect that the P1 and P2 students have likely not been exposed to these FDA-approved products yet in the curriculum.

Students were 95\% confident that Alzheimer's disease and hepatitis were not qualifying conditions for medical cannabis, however, they are qualifying conditions in seven and nine states respectively at the time of survey development (Table 1). ${ }^{1}$ Overall, the results demonstrate a lack of knowledge and confidence in identifying qualifying conditions for medical cannabis in various states. This lack of knowledge and confidence is an important finding as the likelihood of a graduate practicing in one of the 45 states with medical cannabis programs is quite high. When working with patients or providers, they will need to demonstrate at least a basic knowledge of the subject and how medical cannabis use may impact patient care. ${ }^{6,7,20-25}$ For states where pharmacists are engaged in the medical cannabis programs, a strong knowledge base may increase their appeal to employers and lead to additional employment opportunities within pharmacies or 


\section{American Journal of Pharmaceutical Education 2018; 82 (5) Article 6296.}

Table 3. Pharmacy Student Self-Reported Confidence in Various Domains Regarding Medical Cannabis (N=238)

\begin{tabular}{|c|c|c|c|c|}
\hline & $\begin{array}{c}\begin{array}{c}\text { Not } \\
\text { Confident }\end{array} \\
\mathrm{N}(\%)\end{array}$ & $\begin{array}{c}\begin{array}{c}\text { Somewhat } \\
\text { Confident }\end{array} \\
\mathrm{N}(\%)\end{array}$ & $\frac{\text { Confident }}{\mathrm{N}(\%)}$ & $\begin{array}{c}\begin{array}{c}\text { Missing } \\
\text { Response }\end{array} \\
\text { N }(\%)\end{array}$ \\
\hline $\begin{array}{l}\text { I know the pharmacokinetics of cannabis } \\
\text { administered via the inhalation route. }\end{array}$ & $165(69)$ & $52(22)$ & $6(3)$ & $15(6)$ \\
\hline $\begin{array}{l}\text { I know the pharmacokinetics of cannabis } \\
\text { administered via the oral route. }\end{array}$ & $166(69)$ & $50(21)$ & 7 (3) & $15(6)$ \\
\hline $\begin{array}{l}\text { I know how to retrieve drug information related to } \\
\text { the use of cannabis for medical purposes. }\end{array}$ & $92(39)$ & 89 (37) & $41(17)$ & $16(7)$ \\
\hline $\begin{array}{l}\text { I know how to evaluate for drug-cannabis } \\
\text { interactions. }\end{array}$ & $162(68)$ & $51(22)$ & $10(4)$ & $15(6)$ \\
\hline $\begin{array}{l}\text { I know how to evaluate for disease-cannabis } \\
\text { interactions. }\end{array}$ & $170(71)$ & 45 (19) & $8(3)$ & $15(6)$ \\
\hline $\begin{array}{l}\text { I know how to talk to health care providers about } \\
\text { the risks and benefits of cannabis used medically. }\end{array}$ & 149 (63) & $29(12)$ & $10(4)$ & $50(21)$ \\
\hline $\begin{array}{l}\text { I know how to talk with a patient who uses cannabis } \\
\text { medically about the risks of use. }\end{array}$ & $171(72)$ & $44(18)$ & $8(3)$ & $15(6)$ \\
\hline $\begin{array}{l}\text { I know how to talk with a patient who uses cannabis } \\
\text { medically about the benefits of use. }\end{array}$ & $162(68)$ & $50(21)$ & $11(5)$ & $15(6)$ \\
\hline $\begin{array}{l}\text { I know how to talk with a patient about cannabis } \\
\text { dosage forms available. }\end{array}$ & $165(69)$ & $47(20)$ & $11(5)$ & $15(6)$ \\
\hline $\begin{array}{l}\text { I know the pharmacology of cannabinoids and the } \\
\text { receptors they act upon. }\end{array}$ & $114(48)$ & $92(40)$ & $17(7)$ & $15(6)$ \\
\hline
\end{tabular}

the pharmaceutical industry. Pharmacists may also be involved in policy development, both locally and nationally, on the subject. ${ }^{5-7}$

In Moeller and Woods' study of pharmacy students' knowledge of qualifying conditions and adverse reactions, they found that only cancer $(91 \%)$ and glaucoma $(57 \%)$ were identified by over half of their respondents. ${ }^{18}$ In our study, responses were similar for cancer (79\%) and glaucoma $(50 \%)$, however, when including additional confidence measures, the number of correct responses decreased to $33 \%$ and $22 \%$ for cancer and glaucoma, respectively. This demonstrates that even when students are able to identify a few of the more commonly known qualifying conditions (ie, epilepsy, cancer, glaucoma), they are not confident in their responses. This finding may be due to the wide range and variability of qualifying conditions and lack of supporting clinical trials for many conditions where cannabis is permitted for medical use. ${ }^{1,2,20-25}$

Similar to Moeller and Woods' study, we also measured student attitudes and opinions toward medical cannabis use. Our findings show that $85 \%$ of respondents favored medical cannabis use by eligible patients. Among that $85 \%, 40 \%$ indicated that their opinion has become more favorable in the last year. Approximately $8 \%$ of respondents have never supported medical cannabis use by eligible patients. The Moeller study found that $59 \%$ of their respondents supported cannabis for medical use and this support was highest among the subset of previous cannabis users, at $78 \%$. Our study did not adjust for previous cannabis use, which may be a limitation. Additionally, these findings may be influenced by the age and relative clinical experience of the respondents as support for medical cannabis was found to be much higher than among American health care practitioners as described above. ${ }^{11-16}$ It would be interesting to compare attitudes of students to those of current pharmacists to evaluate the influence of age and experience on attitudes toward medical cannabis.

An additional focus of our study was in regard to student attitudes toward "curricular coverage and education" on the topic for pharmacists and pharmacy students (Table 4). Student responses overwhelming favored increasing coverage of the topic, with $93 \%$ of students agreeing with "students in my profession should receive education on the programs/laws for state medical cannabis programs" and $90 \%$ agreed that "education on how to 


\section{American Journal of Pharmaceutical Education 2018; 82 (5) Article 6296.}

Table 4. Pharmacy Student Attitudes on Medical Cannabis Curricula $(\mathrm{N}=238)$

\begin{tabular}{|c|c|c|c|c|}
\hline & $\begin{array}{c}\text { Disagree } \\
\text { N (\%) }\end{array}$ & $\begin{array}{c}\text { Neither } \\
\text { N (\%) }\end{array}$ & $\begin{array}{l}\text { Agree } \\
\text { N (\%) } \\
\end{array}$ & $\begin{array}{c}\text { Missing } \\
\text { Response } \\
\text { N }(\%) \\
\end{array}$ \\
\hline $\begin{array}{l}\text { Medical cannabis education should be part of the } \\
\text { required curriculum in the next } 5 \text { years. }\end{array}$ & $15(6)$ & $47(20)$ & $156(66)$ & $20(8)$ \\
\hline $\begin{array}{l}\text { Medical cannabis education should be part of the elective } \\
\text { curriculum in the next } 5 \text { years. }\end{array}$ & $10(4)$ & $25(11)$ & $183(77)$ & $20(8)$ \\
\hline $\begin{array}{l}\text { The endocannabinoid system should be covered in } \\
\text { physiology and pharmacology classes. }\end{array}$ & $9(4)$ & $35(15)$ & $174(73)$ & $20(8)$ \\
\hline $\begin{array}{l}\text { Education on how to discuss/counsel the risks and } \\
\text { benefits of cannabis use should be included in the } \\
\text { pharmacy curriculum within the next } 5 \text { years. }\end{array}$ & $3(1)$ & $19(8)$ & $195(82)$ & $21(9)$ \\
\hline $\begin{array}{l}\text { Education on the pharmacology of cannabinoids of } \\
\text { cannabis use should be included in the pharmacy } \\
\text { curriculum within the next } 5 \text { years. }\end{array}$ & $4(2)$ & $26(11)$ & 187 (79) & $21(9)$ \\
\hline $\begin{array}{l}\text { Pharmacists should have specific medical education and } \\
\text { training before being able to dispense medical } \\
\text { cannabis products to patients. }\end{array}$ & $8(3)$ & $20(8)$ & $191(80)$ & $19(8)$ \\
\hline $\begin{array}{l}\text { Students in my profession should receive education on the } \\
\text { programs/laws for state medical cannabis programs. }\end{array}$ & $2(1)$ & $14(6)$ & $203(85)$ & $19(8)$ \\
\hline
\end{tabular}

discuss/counsel the risks and benefits of cannabis use should be included in the pharmacy curriculum within the next 5 years."

By using a self-reported confidence measure for various domains (ie, pharmacokinetics, pharmacology, patient education, etc) of medical cannabis use, areas for potential curriculum development were identified (Table 3). Students were most confident in using drug information skills to retrieve information on the subject. They also felt somewhat confident in the pharmacology, endocannabinoid system, and laws regarding medical cannabis. This finding is likely due to responses for the $\mathrm{P} 3$ class, as they received a 90-minute lecture that specifically covered these aspects. Many students are familiar with tetrahydrocannabinol (THC) and its psychoactive effects from their general education and for this reason, may have indicated that they were "somewhat confident" in the pharmacology of cannabis. Finally, there has been much publicity about state laws and non-psychoactive cannabidiol (CBD) for pediatric patients, and students may have been exposed to CBD's pharmacology through the media or other sources.

The results also show that students are not confident in their communication skills regarding medical cannabis. Students need to be educated and build confidence in this area so they can discuss the risks and benefits with patients and providers. Pharmacists are among the most trusted and accessible health professionals and their input will be sought by patients on this controversial treatment option. In fact, $90 \%$ of students agreed that being able to counsel a patient about the risks and benefits of medical cannabis use should be included within the elective (84\%) and/or required (72\%) pharmacy curricula (Table 4).

Currently, there is little coverage of medical cannabis within typical Doctor of Pharmacy curricula. Many schools cover cannabis-based FDA-approved products, but these products only comprise a small percentage of all cannabis products currently available. ${ }^{8-10}$ The findings demonstrate a desire for students to become more knowledgeable in various state laws, which is important because they may practice in a state with a medical cannabis program. Furthermore, students recognize the importance of being able to have an objective conversation with patients about the risks and benefits of medical cannabis use (Table 4). A strength of this study is that it provides the student perspective regarding domains that may be prioritized (Tables 3 and 4). Student recommendations for curricular focus are consistent with previous recommendations for the role of the pharmacist in the publication by Seamon. ${ }^{6}$

There are several limitations of this study. Student knowledge and confidence measures were reported as an aggregate and not separated by year (Table 2). Based on the findings, it was expected that $\mathrm{P} 3$ students would have the highest number of correct responses as they have 


\section{American Journal of Pharmaceutical Education 2018; 82 (5) Article 6296.}

had the most exposure to the subject. The Moeller study had controlled for previous use of cannabis. ${ }^{18}$ Although the authors did measure this variable, it was not included in this publication but will be used in alternative analysis.

When measuring self-reported confidence, it may have been helpful to include a comparator topic (ie, anti-hypertensive drugs) to determine students' level of confidence with a more familiar subject. Perhaps there is a lack of confidence overall among P1 students, and this finding may not be unique to medical cannabis.

Other limitations include the nomenclature or lack of specificity of the qualifying conditions or adverse reactions used in the survey. For example, "hepatitis" may have been a confusing term for students to interpret the context of cannabis use. Therefore, future research in this area should consider more specific terminology for uses/ conditions, although they vary dramatically from state to state in terms of wording. Furthermore, a qualifying condition was considered correct based on state laws as opposed to peer-reviewed evidence to support its use. This may have also been a confounder for students that could be made more explicitly clear. Finally, this study only represents students from one institution. If students around the country were surveyed, it would be interesting to evaluate findings by age, pharmacy class, geographic region or specific state.

This study contributes to the literature in that it measures students' knowledge, confidence and attitudes toward the addition of the subject of medical cannabis to the curricula. Overall, students demonstrate a lack of knowledge of both state-approved medical uses and adverse reactions. The additional measure of confidence provides further insight into their level of appreciation for the subject.

This study also identifies particular domains that should be considered for addition to elective or required curricula. As schools review their curricular mapping, the clinical areas focusing on epilepsy and pain in particular should consider inclusion of the therapeutic use of cannabinoids for these conditions given the increasing prevalence. Additionally, education on cannabis from the substance abuse perspective should be updated to include potential benefits in particular populations that may lead to its use without prescription or oversight from medical professionals. Finally, courses focusing on pharmacy laws should include coverage of the legality of medical cannabis around the country, with focus on the state where the school is located.

\section{CONCLUSION}

This study demonstrates a knowledge gap regarding the indications and adverse reactions related to medical cannabis use among pharmacy students (Table 1). Pharmacy students also expressed a lack of confidence in several domains related to the subject, such as their ability to counsel patients on risks and benefits and knowledge of the various state laws (Table 3 ).

This knowledge gap may be due to the lack of coverage of the topic in their formal training. Students overwhelmingly favored adding content on the subject of medical cannabis to the Doctor of Pharmacy curricula (Table 4). As states continue to allow medical cannabis use, it is imperative that future health professionals are knowledgeable in this area. ${ }^{1,2,6-8}$

Pharmacists will be called upon to evaluate potential drug-drug and drug-disease interactions; perform medication reconciliation accurately; advise patients on risks and benefits; recognize conditions where medical cannabis is considered a legal alternative; and understand the need for standardization and quality control. Additionally, in states such as Minnesota, pharmacists are uniquely positioned to aid with patient education and safety while potentially being engaged in the entrepreneurial aspects of the medical cannabis industry. ${ }^{4,5}$

Pharmacy schools need to consider evaluating current coverage of the subject in multiple areas of the curriculum (ie, physiology, pharmacology, therapeutics, and law). Additional coverage and curricular changes may be warranted to better prepare students for their future practice considering the increased prevalence of medical cannabis use in the United States. As schools review therapeutic topics where medical cannabis is utilized, attempts to include this information within their courses should be considered.

\section{ACKNOWLEGMENTS}

The authors would like to thank Jessin Joseph and Nichole VanDenEng for helping to pilot the questionnaire.

\section{REFERENCES}

1. 29 legal medical marijuana states and DC. ProCon.org. http:// medicalmarijuana.procon.org/view.resource.php?resourceID $=000881$. Accessed May 9, 2017.

2. 17 states with laws specifically about legal cannabidiol (CBD). ProCon.org http://medicalmarijuana.procon.org/view.resource.php? resourceID $=006473$. Accessed May 9, 2017.

3. Friedman D, Devinsky O. Cannabinoids in the treatment of epilepsy. N Engl J Med. 2015;373:1048-1058.

4. Bonner L. Pharmacists take on medical cannabis dispensing role in three states. American Pharmacists Association. https://www. pharmacist.com/pharmacists-take-medical-cannabis-dispensing-rolethree-states. Published January 13, 2016. Accessed November 2, 2016. 5. Medical Cannabis. Minnesota Department of Health. http://www. health.state.mn.us/topics/cannabis/. Accessed January 2, 2017.

6. Seamon MJ, Fass JA, Maniscalco-Feichtl M, Abu-Shraie NA. Medical marijuana and the developing role of the pharmacist. Am J Health Syst Pharm. 2007;64(10):1037-1044. 


\section{American Journal of Pharmaceutical Education 2018; 82 (5) Article 6296.}

7. American Pharmacists Association. Role of the pharmacist in the care of patients using cannabis. 2014-2015 APhA Policy

Committee Report. https://www.pharmacist.com/sites/default/ files/files/Role $\% 20$ of $\% 20$ the $\% 20$ Pharmacist $\% 20$ in $\%$ 20the $\% 20$ Care $\% 20$ of $\% 20$ Patients $\% 20$ Using $\% 20$ Cannabis $\%$ 20.pdf. Accessed May 9, 2017.

8. Aggarwal SK, Carter GT, Sullivan MD, ZumBrunnen C, Morrill R, Mayer JD. Medicinal use of cannabis in the United States: historical perspectives, current trends, and future directions. J Opioid Manag. 2009;5(3):153-168.

9. GW's Epidiolex clinical program. GW Pharmaceuticals. https://www. gwpharm.com/patients-caregivers/patients. Accessed May 9, 2017. 10. Sativex. GW Pharmaceuticals. https://www.gwpharm.com/ products-pipeline/sativex. Accessed May 9, 2017.

11. Doblin RE, Kleiman MA. Marijuana as antiemetic medicine: a survey of oncologists' experiences and attitudes. J Clin Oncol. 1991;9(7):1314-1319.

12. Schwartz RH, Voth EA, Sheridan MJ. Marijuana to prevent nausea and vomiting in cancer patients: a survey of clinical oncologists. South Med J. 1997;90(2):167-172.

13. Charuvastra A, Friedmann PD, Stein MD. Physician attitudes regarding the prescription of medical marijuana. J Addict Dis. 2005;24(3):87-93.

14. Kondrad E, Reid A. Colorado family physicians' attitudes toward medical marijuana. J Am Board Fam Med. 2013;26(1): 52-60.

15. Uritsky TJ, McPherson ML, Pradel F. Assessment of hospice health professionals' knowledge, views, and experience with medical marijuana. J Palliat Med. 2011;14(12): 1291-1295.

16. Adler JN, Colbert JA. Medicinal use of marijuana - polling results. $N$ Engl J Med. 2013;368:e30.
17. Chan MH, Knoepke CE, Cole ML, Mckinnon J, Matlock DD. Colorado medical students' attitudes and beliefs about marijuana. J Gen Intern Med. 2017;32(4):458-463.

18. Moeller KE, Woods B. Pharmacy students' knowledge and attitudes regarding medical marijuana. Am J Pharm Educ. 2015; 79(6):Article 85.

19. Ebert T, Zolotox Y, Eliav S, Ginzburg O, Shapira I, Magnezi R. Assessment of Israeli physicians' knowledge, experience and attitudes towards medical cannabis: a pilot study. IMAJ. 2015; 17(7):437-441.

20. Whiting PF, Wolff RF, Deshpande S, et al. Cannabinoids for medical use: a systematic review and meta-analysis. JAMA. 2015; 313(24):2456-2473.

21. Borgelt LM, Franson KL, Nussbaum AM, Wang GS. The pharmacologic and clinical effects of medical cannabis.

Pharmacotherapy. 2013;33(2):195-209.

22. Hill KP. Medical marijuana for treatment of chronic pain and other medical and psychiatric problems: a clinical review. JAMA. 2015;313(24):2474-2483.

23. Koppel BS, Brust JC, Fife T, et al. Systematic review: efficacy and safety of medical marijuana in selected neurologic disorders report of the Guideline Development Subcommittee of the American Academy of Neurology. Neurology. 2014;82(17):1556-1563.

24. Ben Amar M. Cannabinoids in medicine: a review of their therapeutic potential. J Ethnopharmacol. 2006;105(1-2):1-25.

25. The Health Effects of Cannabis and Cannabinoids: The Current State of Evidence and Recommendations for Research. Committee on the Health Effects of Marijuana: An Evidence Review and Research Agenda. Board on Population Health and Public Health Practice; Health and Medicine Division; National Academies of Sciences, Engineering and Medicine. http://www.nap.edu/24625. Accessed January 15, 2017. 